\title{
Evaluation of a Harmony Search Algorithm for Manual Lifting Tasks Optimization
}

\author{
Serap Ulusam Seçkiner \\ Gaziantep University, Faculty of Engineering, \\ Department of Industrial Engineering \\ 27310, Şehitkamil / Gaziantep / Turkey
}

\author{
Yunus Eroğlu \\ Gaziantep University, Faculty of Engineering, \\ Department of Industrial Engineering \\ 27310, Şehitkamil / Gaziantep / Turkey
}

\begin{abstract}
This paper presents near optimal solution method to find safe work place design using harmony search algorithm. Revised NIOSH equations are considered to minimize relative estimate of the physical stress associated with a manual-lifting job. The proposed algorithm will assist occupational safety and health practioners in evaluating lifting tasks and reducing the incidence of low back injuries in workers.
\end{abstract}

\section{General Terms}

Algorithms, Heuristics, Ergonomics, Work Design.

\section{Keywords}

Lifting, Harmony Search Algorithm, Workplace, Design.

\section{INTRODUCTION}

Manual work design is the process of designing work according to human capabilities and limitations. Lifting processes as manual work have commonly variety of postures problems that always considering the pressures on the musculoskeletal system. Low back injuries are common and frequent health problems for many workers who lift materials [1], [2]. Low back pain occurs generally as a result of incorrect and bad lifting methods. Its frequency is associated with lifting repetition, bending and twisting motions of the torso [3]. It can be considered as an expensive health problem for employees because of paying not only for workers' compensation, but also spending more on tests, treatments, claims, and surgeries [4], [5]. In general; job physical factors, worker demographics, past low back pain history, psychosocial factors, hobbies, and physical activities outside of work can be listed as main causes of low back pain [6], [7]. There are several studies including associations between job physical factors and [1], [8]-[10].

National Institute of Occupational Safety and Health developed NIOSH Lifting Equation to evaluate two-handed lifting tasks in 1981 and revised in 1993. The equation was designed to assist in the identification of ergonomic solutions for reducing the physical stresses associated with manual lifting. The revised NIOSH Lifting Equation commonly used to quantify biomechanical stressors to low back from lifting and lowering of materials [11]-[15]. The revised equation evaluates two main parameters, Recommended Weighted Limit (RWL) and Lifting Index (LI), to determine the safety level of lifting procedure [16], [17].

Manual lifting problem can be explained with RWL and LI and especially at the lifting design level, but unfortunately, even in its simplest forms, it is an intractable NP hard optimization problem. Exact methods can be rarely adopted and, for problems of practical interest, the idea of global optimization must be abandoned in favour of the search of good and feasible solutions.
Concerning the solution approach, since the problem is NP hard, a novel meta-heuristic is proposed based on the Harmony Search (HS), a recent algorithm in the family of the population based evolutionary heuristics [18], which has proven its effectiveness in solving NP-hard combinatorial problems [19]. The algorithm's global search capabilities are evaluated using a previously published suite of difficult analytical genetic algorithm test problems [5] while its sensitivity to lifting design variables scaling is given mathematically by NIOSH and verified using various lifting conditions. For both categories of problems, HS robustness and performance are compared to genetic algorithm (GA). This study contributes to a better understanding of the revised NIOSH Lifting Equation applied to field conditions by providing a detailed description of the procedures for measuring its variables.

The paper is structured as follows. Section 2 introduces the basic notation and gives full details concerning the recommended weight limit and lifting index for manual lifting problem. The meta-heuristic used to find an optimal solution is explained in Sections 3 and it is validated in Sections 4. To this aim a comprehensive set of manual lifting problems is generated and solved, using as benchmark two alternative heuristics (purposely developed to this scope) and a recent genetic algorithm developed by Carnahan and Redfern (1998) [11]. Lastly, conclusions and directions for future works are given in Section 5.

\section{PROBLEM FORMULATION}

\subsection{Recommended Weight Limit (RWL)}

The RWL is the principal product of the revised NIOSH lifting equation. There are many factors that can affect a lifting operation and it is important that personnel involved in lifting operations are aware of such factors. These factors are Load Weight (L); Weight of the object to be lifted, Horizontal Location (H); Distance of the hands away from the mid-point between the ankles, Vertical Location (V); Distance of the hands above the floor, Vertical Travel Distance (D); Absolute value of the difference between the vertical heights at the destination and origin of the lift, Asymmetry Angle (A); Angular measure of how far the object is displaced from the front (mid-sagittal plane) of the worker's body at the beginning or ending of the lift, Neutral Body Position; the position of the body when the hands are directly in front of the body and there is minimal twisting at the legs, torso, or shoulders. The asymmetry angle is defined by the location of the load relative to the worker's mid-sagittal plane, as defined by the neutral body posture, rather than the position of the feet or the extent of body twist, Lifting Frequency (F); Average number of lifts per minute over a 15 minute period, Lifting Duration; Three-tiered classification of lifting duration specified by the distribution of work-time and recovery time, 
Coupling Classification; Classification of the quality of the hand-to-object coupling quality is classified as good, fair, or poor, and finally Significant Control; A condition requiring precision placement of the load at the destination of the lift. This is usually the case when the worker has to re-grasp the load near the destination of the lift, or the worker has to momentarily hold the object at the destination, or the worker has to carefully position or guide the load at the destination [16].

RWL is equal to multiplication of load constant, horizontal multiplier, vertical multiplier, distance multiplier, frequency multiplier, asymmetry multiplier and coupling quality multiplier (Eq. 1).

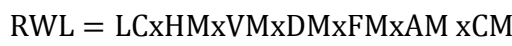

Where;

LC: Load Constant $=23 \mathrm{~kg}$,

HM: Horizontal Multiplier,

VM: Vertical Multiplier,

DM: Distance Multiplier,

AM: Asymmetric Multiplier,

FM: Frequency Multiplier,

CM: Coupling Multiplier,

Also, the values of these multipliers can be computed as LC is equal to $23 \mathrm{~kg}, \mathrm{HM}$ is equal to $(25 / \mathrm{H}), \mathrm{VM}$ is equal to 1 $(0.003|\mathrm{~V}-75|), \mathrm{DM}$ is equal to $0.82+(4.5 / \mathrm{D}), \mathrm{AM}$ is equal to 1-(0.0032A), FM and CM are taken from lookup tables in NIOSH reference guide [16] or one can directly get all them from lookup tables in NIOSH [16].

\subsection{Lifting Index (LI)}

Before discussing the standardized goodness, the importance and meaning of Lifting Index (LI) have to be clearly explained. It is a term that provides a relative estimate of the level of physical stress associated with a particular manual lifting task and equals to load weight divided by RWL (Eq. 2) [16].

\section{$\mathrm{LI}=(\mathrm{Wt}) / \mathrm{RWL}$}

There are several studies which conclude that lifting tasks with a Lifting Index greater than 1.0 pose an increased risk for lifting-related low back pain [1], [3], [7], [16], [17], [20]. The greater LI is, the more LBP risk occurs. Any increase of LI causes increase of the level of the risk for the worker. Thus, a greater percentage of workforces are likely to be at risk for developing lifting-related low back pain. Therefore, the goal should be to design the lifting jobs to achieve a LI of 1.0 or less.

The manual lifting problem has design parameters of workspace. The environmental conditions are established by setting the constraints on the solutions. These are weight of the load handled $(\mathrm{kg})$, Quality of the handle interface (good, poor, fair), The number of lifts needed for one operator, Minimum and maximum allowed time to perform the lifts and an acceptable Lifting Index (LI) determined by ergonomist. The first and the second environmental parameters are constrains of lifted load. The third and the forth environmental parameter constitute demands of lifted load and an acceptable Lifting Index (LI) gives the safety concerns of the ergonomist.

Horizontal distance from load to ankles, asymmetric angle between load and sagittal plane, vertical distance of hands from floor-end to lift, vertical distance of hands from floorstart to lift, and duration of lifting procedure are used as design parameters of the manual lifting problem. The acceptable and operational limits of these parameters determined by NIOSH (1994) are given in Table 1. All these design parameters were evaluated by Harmony Search algorithm and two types of goodness function, Recommended Weight Limit as Raw Goodness and Standardized Goodness, was considered as fitness value. These are quantifiable measures of how well the solution meets the productivity and safety constraints that comprise the environment conditions for lifting design problem.

Table 1. Design parameters of evaluated lifting problem

\begin{tabular}{llll}
\hline Parameter & Definition & Min. & Max. \\
\hline $\mathbf{H}$ & $\begin{array}{l}\text { Horizontal } \\
\text { distance (load to } \\
\text { ankles) }\end{array}$ & $\begin{array}{l}25.4 \\
(\mathrm{~cm})\end{array}$ & $63.5(\mathrm{~cm})$ \\
$\mathbf{A}$ & $\begin{array}{l}\text { Asymmetry } \\
\text { (between load and }\end{array}$ & $0(\mathrm{deg})$ & $135(\mathrm{deg})$ \\
& $\begin{array}{l}\text { sagittal plane) } \\
\text { Vertical distance } \\
\text { (hands to floor- }\end{array}$ & $0(\mathrm{~cm})$ & $177.8(\mathrm{~cm})$ \\
$\mathbf{V}_{\mathbf{e}}$ & $\begin{array}{l}\text { end to lift) } \\
\text { Vertical distance } \\
\text { (hands to floor- }\end{array}$ & $0(\mathrm{~cm})$ & $177.8(\mathrm{~cm})$ \\
$\mathbf{V}_{\mathbf{s}}$ & $\begin{array}{l}\text { start to lift) } \\
\text { Duration of lifting } \\
\text { task }\end{array}$ & Min (h) & $\operatorname{Max}(\mathrm{h})$ \\
$\mathbf{D}$ & & \\
\hline
\end{tabular}

3. HARMONY SEARCH ALGORITHM

\subsection{Basic Features}

There are many different optimization techniques to solve lifting design problems [21]. While gradient-based nonlinear programming is the most widely used one, it may become difficult and unstable when the objective function and constraints have multiple or sharp peaks [19]. A successful strategy, a Genetic Algorithm, was suggested to get more than suitable solutions for lifting design problems by Carnahan and Redfern [11]. In the same objective, Harmony Search algorithm was selected to evaluate adjustable lifting designs.

There are several studies considering that music is a satisfying processes in shopping, education, productivity for workers, and even in surgery process [22]-[27]. This inspired Geem et. al. [18] to produce a new heuristic algorithm derived from an artificial phenomenon found in musical performance. While musical performances seek a best harmony by using different instruments and written music, the optimization algorithms seek a best state (global optimum - minimum cost or maximum benefit or efficiency) determined by objective function evaluation [18]. The harmony in music can be thought as the optimization solution vector, and the musicians' improvisations are similar with local and global search schemes in optimization techniques [19]. The advantages of Harmony search can be listed as follows;

- It does not require initial values,

- It uses a stochastic random search so that derivative information is unnecessary,

- It needs fewer mathematical requirements than other heuristics/meta-heuristics,

- It can be easily adopted for various types of engineering optimization problems.

Recent studies show its implementation capability to different type of optimization problems. Sabar and Kendall [28] used it to select portfolio, Gao et. al. [29] proposed a job shop 
scheduling problem, and Maheri and Narimani [30] used it in a design problem of side sway steel frames. These examples can easily multipliable by searching current literature. In the light of all these positive characteristics of Harmony Search algorithm is a competitive method to find optimal work designs in lifting problems.

\section{Table 2. The behavior while playing music versus} harmony search (Lee and Geem, 2005)

\begin{tabular}{ll}
\hline \multicolumn{1}{c}{ Playing Music } & \multicolumn{1}{c}{ Harmony Search } \\
\hline $\begin{array}{l}\text { Playing any one pitch } \\
\text { from his (or her) memory }\end{array}$ & $\begin{array}{l}\text { Choosing any one value from } \\
\text { the HS memory }\end{array}$ \\
Playing an adjacent pitch & $\begin{array}{l}\text { Choosing an adjacent value of } \\
\text { of one pitch from his (or } \\
\text { one value from the HS } \\
\text { memory memory }\end{array}$ \\
$\begin{array}{l}\text { Playing totally random } \\
\text { pitch from the possible }\end{array}$ & $\begin{array}{l}\text { Choosing totally random } \\
\text { range }\end{array}$ \\
sound range &
\end{tabular}

The behavior of a musician can be summarized as in Table 2 . It can be seen that the similarity between music playing procedure and optimum point searching procedure of Harmony Search. The main steps of Harmony Search are as follows [19]:

i. Initialize the optimization problem and algorithm,

ii. Initialize the harmony memory (HM),

iii. Improvise a new harmony from HM.

iv. Update the HM,

v. If stopping criteria are not satisfied, go step ii.

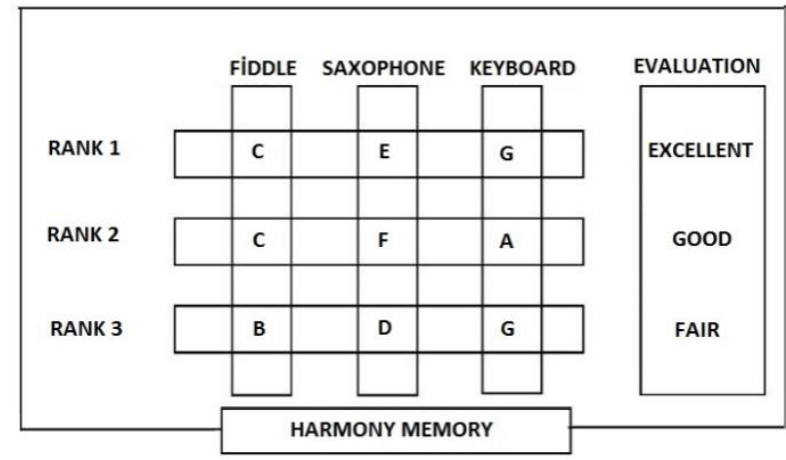

Fig.1. Structure of Harmony Memory (Geem et al., 2001)

Figure 1 gives the main Harmony Memory structure. There are three instruments as of fiddle, saxophone, and keyboard. Initially, all instruments have their memories with random harmonies (step ii): (C, E, G), (C, F, A), and (B, D, G) that are sorted by aesthetic estimation. In step iii, three instruments produce a new harmony; for example, $(\mathrm{B}, \mathrm{E}, \mathrm{G})$ ) fiddle sounds $\{B\}$ out of $\{C, C, B\}$; saxophone sounds $\{E\}$ out of $\{E, F$, $D\}$; and keyboard sounds $\{\mathrm{G}\}$ out of $\{\mathrm{G}, \mathrm{A}, \mathrm{G}\}$. This procedure is an equally random selection from $\mathrm{HM}$ of each instrument with a probability of $33.3 \%$ for any note. Step iv suggests the updating HM with better results. If the new harmony $(\mathrm{B}, \mathrm{E}, \mathrm{G})$ is better than any of the existing harmonies in the HM, the new harmony is included in HM and the worst harmony (in this example, $(\mathrm{B}, \mathrm{D}, \mathrm{G})$ ) is excluded from the HM. Then the termination criteria are checked to stop algorithm (step v).

Harmony Search algorithm has two main parameters, Harmony Memory Consideration Rate (HMCR) and Pitch
Adjusting Rate (PAR) which get values between 0 and 1 . HMCR is needed in the case that all optimum decision parameters do not exist initially in HM. If a uniformly generated value between 0 and 1 occurs above the HMCR, then Harmony Memory finds notes randomly within the possible playable range without considering HM [18]. The PAR is introduced to escape local optima and mimics the pitch adjustment of each instrument. It works by shifting to neighboring values within a range of possible values. If there exist five possible design variables such as $\{2,7,5,8,-4\}$, $\{5\}$ can be moved to neighboring $\{7\}$ or $\{8\}$ in the pitch adjusting procedure [18]. These parameter are generally set as HMCR is between 0.7 and 0.9 , PAR is between 0.1 and 0.5 [31].

\subsection{Proposed Algorithm}

Environmental conditions of the lifting problem can be considered as task requirements so that the Harmony Search could generate new design solutions. This algorithm finds alternative solutions, with a number of Harmony Memory size, within environmental conditions. The evaluation stages of the Harmony Search algorithm are given as follows;

i. Initialize the optimization problem and algorithm,

Harmony Search algorithm searches optimal design parameters for lifting that will meet the environmental conditions. So, all environmental conditions must be determined at the beginning. In this study, the load weight $(\mathrm{Kg})$, handle interface of the material, number of lifts, lifting time range (hour), and Lifting Index was determined as environmental conditions (Table 2).

ii. Initialize the harmony memory (HM),

Harmony Search algorithm randomly generates 200 variable design solutions, which is the Harmony Memory Size, within given limits as in Table 1. Each solution is a linear array of five real numbers. This array shows five constraints for lifting workplace design.

Randomly generated three harmonies can be seen in Table 3 . In this stage, Harmony Search evaluates goodness for all HM.

iii. Improvise a new harmony from HM.

A new harmony is generated by considering HMCR and PAR. The goodness of new harmony is evaluated.

iv. Update the HM,

If the new harmony is better than any of existing one, it is added to HM and the worst one is removed from HM.

v. If stopping criteria are not satisfied, go step ii.

The stopping criterion for this study is reaching a maximum iteration number which is set 2500 .

Table 3. Example of an initial randomly generated three harmonies in harmony memory

\begin{tabular}{llllll}
\hline Harmony & $\begin{array}{l}\mathrm{H} \\
(\mathrm{cm})\end{array}$ & $\begin{array}{l}\mathrm{A} \\
(\mathrm{deg})\end{array}$ & $\mathrm{Ve}(\mathrm{cm})$ & $\begin{array}{l}\text { Vs } \\
(\mathrm{cm})\end{array}$ & $\mathrm{D}(\mathrm{h})$ \\
\hline 1 & 30.7 & 2 & 41.1 & 127.2 & 115.3 \\
2 & 22.5 & 105.7 & 85.9 & 17.7 & 109.5 \\
3 & 27.6 & 3.8 & 95 & 64.3 & 30.6 \\
\hline
\end{tabular}

\subsection{Test Problems}

The lifting process may have different physical conditions according to the lifting object, productivity plans, and 
workplace limitations. In this study, six different work environments in the current literature [11] were considered to find optimal design parameters (Table 4). These conditions are common work environments with a variety of production demands and lifting indices and can be summarized as follows;

Table 4. Test problems (Carnahan and Redfern, 1998)

\begin{tabular}{llcccc}
\hline Env. & $\begin{array}{l}\text { Weight } \\
(\mathrm{Kg})\end{array}$ & $\begin{array}{c}\text { Coupling } \\
\text { Quality }\end{array}$ & $\begin{array}{c}\text { Number } \\
\text { of lifts }\end{array}$ & $\begin{array}{l}\text { Duration } \\
(\mathrm{h})\end{array}$ & LI \\
\hline Con.1 & 9.0927 & Good & 600 & $0.0-2.0$ & 1.0 \\
Con.2 & 4.5463 & Poor & 200 & $0.0-0.6$ & 1.0 \\
Con.3 & 18.1447 & Poor & 900 & $3.0-8.0$ & 2.0 \\
Con.4 & 31.8042 & Good & 300 & $0.0-8.0$ & 2.0 \\
Con.5 & 47.7064 & Fair & 100 & $0.3-3.3$ & 3.0 \\
Con.6 & 5.4332 & Fair & 2400 & $4.0-8.0$ & 1.0 \\
\hline
\end{tabular}

Condition 1: The lifted load has a moderate weight with $9.0923 \mathrm{~kg}$. It has a good handles. 600 lifting are required for a worker. The lifting duration must be in the range of $0-2$ hours. It can be considered as safe lifting procedure with LI 1.0 .

Condition 2: A safe lifting procedure with a light material, which has bad handles. 200 lifting are required with a duration range between $0-0.6$ hour.

Condition 3: A frequent repetitive lifting job with a load of $18.1447 \mathrm{~kg}$ which has poor handles. The lifting duration range is between 3.0- 8.0 hours and desired lifting index is 2.0.

Condition 4: Considers a lifted load is $31.8042 \mathrm{~kg}$ with good handles. 300 lifting is required with a duration range is between $0-8.0$ hour. The LI is selected as 2.0 by the ergonomist.

Condition 5: This environment has the highest lifted load as $47.7064 \mathrm{~kg}$ with fair handles. 100 lifting are required and lifting duration range is between 0.3-3.3 hours. The ergonomist considers this environment as a risky job with LI 3.0.

Condition 6: This environment has the most frequent lifting with 2400 . The lifted load is light and coupling quality constraint is fair. The time range is between 4.0- 8.0 hours. The $\mathrm{LI}$ is decided as 1.0.

\section{COMPERATIVE ANALYSIS AND RESULTS}

In order to compute sensitivity of proposed algorithm, 10 runs were produced for each of the six conditions. Harmony Search algorithm parameters were set as follows;

Number of iterations: 2500, Harmony Memory size: 200, HMCR: 0.70, PAR: 0.10 .

As the best harmony was created, the algorithm also recorded the current iteration number, LI, and RWL for best harmony. After 10 run performed for each six work environment, 10 possible designs, the best of run design solutions for each harmony, were discussed and compared with Genetic Algorithm solutions. Table 5 summarizes the comparison of results by considering evaluated RWL and LI values. Harmony Search algorithm generated a bit better results than Genetic Algorithm especially for conditions with safe lifting tasks.
Table 5. RWL an LI of Genetic Algorithm versus Harmony Search

\begin{tabular}{ccccc}
\hline Condition & GA & HS & GA & HS \\
\hline & RWL & RWL & LI & LI \\
1 & 9.0966 & 9.0927 & 1.00 & 1.00 \\
2 & 4.5494 & 4.5463 & 1.00 & 1.00 \\
3 & 9.2721 & 9.0724 & 2.00 & 2.00 \\
4 & 15.9021 & 15.9020 & 2.00 & 2.00 \\
5 & 15.9021 & 15.9021 & 3.00 & 3.00 \\
6 & 5.5637 & 5.4332 & 1.00 & 1.00 \\
\hline
\end{tabular}

\subsection{Performing 600 lifts at $9.0723 \mathrm{~kg}$ per lift (Condition 1)}

The first workplace environment has a relatively light load lifted 600 times within a 2-hour time period. 10 Run Harmony Search algorithms find optimal design parameters for the first condition (Table 6).

There are many different suggestions for manual lifting design parameters by considering environmental limits. Although Harmony Search suggests high variable design parameters, algorithm could find desired lifting index value with an acceptable standard deviation and mean in different best combinations. If these results need more explanation, let us give an example;

$\# 2$, the loads can be grasped from 25.4 to $27 \mathrm{~cm}$ horizontally away from ankles with the starting height of the lift varying from 25.4 to $83 \mathrm{~cm}$ with up to $18^{\circ}$ movement in horizontal plane. In order to meet safety and productivity requirements, the design would require that lifts be performed at a rate of approximately 5.7 lifts per minute for 105 minutes. All designs suggest nearly 5 or 6 lifts per minute for nearly 110 minutes. Under these conditions lifting index (LI) is 1.0 as desired, so \#2 has proper design solutions and can be applicable in a real life. Carnahan and Redfern [11] also suggest different design solutions which satisfy desired lifting index and environmental conditions.

\subsection{Performing 200 lifts at $4.5463 \mathrm{~kg}$ per lift (Condition 2)}

The second workplace environment has a light load with only 200 total lifts and poor handle interface coupling required. Table 7 contains the best 10 solutions evolved under Condition 2 , which are very different in design variables but consistent in LI and RWL. For example, in solution 5, the loads can be grasped between 25.4 and $36 \mathrm{~cm}$ horizontally away from the ankles at the start of the lift; however with a very low degree of asymmetry $\left(2.4^{\circ}\right)$. The design would require that lifts be performed at a rate of approximately 10.8 lifts per minute for 18.49 minutes as a maximum allowable time. As desired, these design parameters provide Recommended Weight Limit and Lifting index as $4.5463 \mathrm{~kg}$ and 1.0 respectively. Similarly, genetic algorithm provides desired RWL and LI in condition 2 [11]. 
Table 6. Near-optimal design of lifting task 1 - results of 10 run for the first environment

\begin{tabular}{lccccccccc} 
& & & \multicolumn{3}{c}{ Found } & \multicolumn{7}{c}{ Harmony } \\
\cline { 2 - 9 } & LI & RWL & $\begin{array}{c}\text { Iteration } \\
\text { RUN }\end{array}$ & H & A & Ve & Vs & D & $\begin{array}{c}\text { \#of } \\
\text { Lifts/min }\end{array}$ \\
\hline 1 & 1 & 9,0929 & 1678 & 33 & 33 & 71 & 7,3 & 116 & 5,1 \\
2 & 1 & 9,0927 & 1336 & 27 & 18 & 83 & 134 & 105 & 5,7 \\
3 & 1 & 9,0921 & 632 & 28 & 11 & 156 & 14 & 120 & 5 \\
4 & 1 & 9,0926 & 104 & 25 & 34 & 20 & 24 & 106 & 5,6 \\
5 & 1 & 9,0925 & 534 & 29 & 48 & 35 & 6,1 & 118 & 5 \\
6 & 1 & 9,0925 & 927 & 30 & 5,5 & 66 & 77 & 113 & 5,3 \\
7 & 1 & 9,0926 & 369 & 29 & 18 & 55 & 83 & 117 & 5,1 \\
8 & 1 & 9,0927 & 1828 & 32 & 25 & 102 & 9,8 & 120 & 5 \\
9 & 1 & 9,0927 & 2139 & 27 & 10 & 59 & 4,4 & 93,7 & 6,4 \\
10 & 1 & 9,0931 & 134 & 30 & 8 & 71 & 48 & 107 & 5,5 \\
\hline
\end{tabular}

Table 7. Near-optimal design of lifting task 2 - results of 10 run for the first environment

\begin{tabular}{lccccccccc} 
& & & \multicolumn{3}{c}{ Found } & \multicolumn{5}{c}{ Harmony } \\
\cline { 2 - 9 } & RI & RWL & $\begin{array}{c}\text { Iteration } \\
\text { RUN }\end{array}$ & H & A & Ve & Vs & D & $\begin{array}{c}\text { \#of } \\
\text { Lifts/min }\end{array}$ \\
\hline 1 & 1 & 4,5463 & 2140 & 42 & 56 & 108 & 12 & 21,1 & 9,4 \\
2 & 1 & 4,5463 & 1210 & 42 & 125 & 18 & 3,3 & 29,8 & 6,7 \\
3 & 1 & 4,5463 & 1355 & 35 & 126 & 143 & 69 & 31,5 & 6,3 \\
4 & 1 & 4,5463 & 999 & 57 & 20 & 124 & 27 & 25,8 & 7,7 \\
5 & 1 & 4,5463 & 2005 & 36 & 2,4 & 155 & 19 & 18,4 & 10,8 \\
6 & 1 & 4,5463 & 1626 & 52 & 54 & 167 & 3,2 & 33,1 & 6 \\
7 & 1 & 4,5463 & 1364 & 38 & 113 & 16 & 60 & 28,3 & 7 \\
8 & 1 & 4,5463 & 1574 & 54 & 113 & 88 & 13 & 34,9 & 5,7 \\
9 & 1 & 4,5463 & 1417 & 48 & 118 & 119 & 7,7 & 35,2 & 5,6 \\
10 & 1 & 4,5463 & 869 & 41 & 114 & 59 & 5,7 & 24,4 & 8,1 \\
\hline
\end{tabular}

Table 8. Near-optimal design of lifting task 3 - results of 10 run for the first environment

\begin{tabular}{|c|c|c|c|c|c|c|c|c|c|}
\hline \multirow[b]{2}{*}{ RUN } & \multirow[b]{2}{*}{ LI } & \multirow[b]{2}{*}{ RWL } & \multirow{2}{*}{$\begin{array}{c}\text { Found } \\
\text { Iteration }\end{array}$} & \multicolumn{6}{|c|}{ Harmony } \\
\hline & & & & $\mathrm{H}$ & A & $\mathrm{Ve}$ & Vs & $\mathrm{D}$ & $\begin{array}{c}\text { \#of } \\
\text { Lifts/min }\end{array}$ \\
\hline 1 & 2 & 9,0724 & 35 & 28 & 25 & 97 & 59 & 436 & 2 \\
\hline 2 & 2 & 9,0724 & 1486 & 32 & 34 & 83 & 1 & 431 & 2 \\
\hline 3 & 2 & 9,0723 & 983 & 31 & 0 & 57 & 73 & 441 & 2 \\
\hline 4 & 2 & 9,0724 & 2436 & 27 & 26 & 83 & 0,9 & 270 & 3,3 \\
\hline 5 & 2 & 9,0724 & 199 & 27 & 46 & 96 & 72 & 470 & 1,9 \\
\hline 6 & 2 & 9,0724 & 193 & 27 & 8,3 & 147 & 13 & 373 & 2,4 \\
\hline 7 & 2 & 9,0721 & 1 & 27 & 40 & 69 & 53 & 354 & 2,5 \\
\hline 8 & 2 & 9,0723 & 1309 & 26 & 56 & 126 & 13 & 460 & 1,9 \\
\hline 9 & 2 & 9,0726 & 2401 & 32 & 27 & 103 & 0,3 & 468 & 1,9 \\
\hline 10 & 2 & 9,0723 & 1049 & 32 & 16 & 66 & 44 & 459 & 1,9 \\
\hline
\end{tabular}


Table 9. Near-optimal design of lifting task 4 - results of 10 run for the first environment

\begin{tabular}{|c|c|c|c|c|c|c|c|c|c|}
\hline \multirow[b]{2}{*}{ RUN } & \multirow[b]{2}{*}{ LI } & \multirow[b]{2}{*}{ RWL } & \multirow{2}{*}{$\begin{array}{l}\text { Found } \\
\text { Iteration }\end{array}$} & \multicolumn{6}{|c|}{ Harmony } \\
\hline & & & & $\mathrm{H}$ & A & $\mathrm{Ve}$ & Vs & $\mathrm{D}$ & $\begin{array}{c}\text { \#of } \\
\text { Lifts/min }\end{array}$ \\
\hline 1 & 2 & 15,9048 & 2371 & 26 & 21 & 85 & 14 & 377 & 0,7 \\
\hline 2 & 2 & 15,8963 & 2033 & 26 & 22 & 75 & 6,2 & 407 & 0,7 \\
\hline 3 & 2 & 15,902 & 2353 & 27 & 20 & 69 & 2,9 & 460 & 0,6 \\
\hline 4 & 2 & 15,9026 & 951 & 26 & 8,4 & 59 & 3,4 & 304 & 0,9 \\
\hline 5 & 2 & 15,9044 & 2100 & 26 & 21 & 77 & 15 & 401 & 0,7 \\
\hline 6 & 2 & 15,9015 & 1652 & 26 & 5,6 & 48 & 15 & 408 & 0,7 \\
\hline 7 & 2 & 15,9023 & 621 & 27 & 20 & 82 & 13 & 109 & 2,7 \\
\hline 8 & 2 & 15,9 & 1092 & 26 & 0,5 & 99 & 22 & 426 & 0,7 \\
\hline 9 & 2 & 15,8969 & 277 & 27 & 3,4 & 78 & 13 & 356 & 0,8 \\
\hline 10 & 2 & 15,9026 & 1355 & 28 & 3,7 & 82 & 2,4 & 384 & 0,7 \\
\hline
\end{tabular}

Table 10. Near-optimal design of lifting task 5 - results of 10 run for the first environment

\begin{tabular}{|c|c|c|c|c|c|c|c|c|c|}
\hline \multirow[b]{2}{*}{ RUN } & \multirow[b]{2}{*}{ LI } & \multirow[b]{2}{*}{ RWL } & \multirow{2}{*}{$\begin{array}{l}\text { Found } \\
\text { Iteration }\end{array}$} & \multicolumn{6}{|c|}{ Harmony } \\
\hline & & & & $\mathrm{H}$ & A & $\mathrm{Ve}$ & Vs & $\mathrm{D}$ & $\begin{array}{c}\text { \#of } \\
\text { Lifts/min }\end{array}$ \\
\hline 1 & 3 & 15,902 & 586 & 26 & 0,4 & 120 & 45 & 46,5 & 2,1 \\
\hline 2 & 3 & 15,9023 & 1403 & 27 & 9,3 & 118 & 0,2 & 82,3 & 1,2 \\
\hline 3 & 3 & 15,9027 & 2174 & 26 & 25 & 83 & 4,8 & 126 & 0,7 \\
\hline 4 & 3 & 15,9019 & 2287 & 30 & 16 & 88 & 4,9 & 54,1 & 1,8 \\
\hline 5 & 3 & 15,9012 & 2079 & 26 & 40 & 63 & 0,9 & 87,3 & 1,1 \\
\hline 6 & 3 & 15,9021 & 1772 & 27 & 25 & 92 & 9,3 & 29,5 & 3,3 \\
\hline 7 & 3 & 15,902 & 287 & 27 & 11 & 39 & 1,6 & 42,5 & 2,3 \\
\hline 8 & 3 & 15,9024 & 1015 & 28 & 21 & 67 & 13 & 98,5 & 1 \\
\hline 9 & 3 & 15,9022 & 1736 & 26 & 9,7 & 123 & 33 & 120 & 0,8 \\
\hline 10 & 3 & 15,9024 & 1187 & 26 & 17 & 38 & 15 & 115 & 0,8 \\
\hline
\end{tabular}

Table 11. Near-optimal design of lifting task 6 - results of 10 run for the first environment

\begin{tabular}{|c|c|c|c|c|c|c|c|c|c|}
\hline \multirow[b]{2}{*}{ RUN } & \multirow[b]{2}{*}{ LI } & \multirow[b]{2}{*}{ RWL } & \multirow{2}{*}{$\begin{array}{c}\text { Found } \\
\text { Iteration }\end{array}$} & \multicolumn{6}{|c|}{ Harmony } \\
\hline & & & & $\mathrm{H}$ & A & $\mathrm{Ve}$ & Vs & $\mathrm{D}$ & $\begin{array}{c}\text { \#of } \\
\text { Lifts/min }\end{array}$ \\
\hline 1 & 1 & 5,4334 & 856 & 26 & 20 & 72 & 5 & 404 & 5,9 \\
\hline 2 & 1 & 5,4333 & 516 & 26 & 6,9 & 156 & 25 & 448 & 5,3 \\
\hline 3 & 1 & 5,4333 & 987 & 26 & 16 & 51 & 8,2 & 418 & 5,7 \\
\hline 4 & 1 & 5,4336 & 463 & 27 & 50 & 56 & 22 & 465 & 5,1 \\
\hline 5 & 1 & 5,4333 & 1591 & 28 & 52 & 96 & 20 & 468 & 5,1 \\
\hline 6 & 1 & 5,4332 & 2198 & 28 & 34 & 85 & 36 & 450 & 5,3 \\
\hline 7 & 1 & 5,433 & 1167 & 33 & 26 & 75 & 2,5 & 465 & 5,1 \\
\hline 8 & 1 & 5,4332 & 297 & 28 & 42 & 95 & 41 & 479 & 5 \\
\hline 9 & 1 & 5,4332 & 2223 & 29 & 6,2 & 94 & 76 & 454 & 5,2 \\
\hline 10 & 1 & 5,4331 & 1654 & 30 & 0,6 & 61 & 5,5 & 432 & 5,5 \\
\hline
\end{tabular}




\subsection{Performing 900 lifts at $18.1447 \mathrm{~kg}$ per lifts (Condition 3)}

The third environmental conditions have a high number of lifts with a moderate load $18.1447 \mathrm{~kg}$ and poor handle interface coupling quality. The best 10 solutions evolved under Condition 3 can be seen in Table 8. The designer from previous conditions as 2.0 differently chooses the LI. This means that this workplace environment is not as safe as first two conditions. Let us give an example design that is evaluated by Harmony Memory.

The first lifting design can be read as follows; the loads can be grasped between 25.4 and $28 \mathrm{~cm}$ horizontally away from the ankles at the start of the lift. The amount of asymmetry angle is set as $25^{\circ}$. The operator has to lift at an average rate of 2 lifts per minute for relatively high duration of 436 minutes. These design parameters provide Recommended Weight Limit and Lifting index as $9.0724 \mathrm{~kg}$ and 2.0 respectively.

\subsection{Performing 300 lifts at $31.8042 \mathrm{~kg}$ per lift (Condition 4)}

The forth workplace environment consists of a heavier load with fewer repetitions. Table 9 presents the best 10 solutions under Condition 4. In solution \#2, the loads can be grasped between 25.4 and $26 \mathrm{~cm}$ horizontally away from the ankles at the start of the lift. The amount of asymmetry angle is set as $21^{\circ}$. The allowable vertical height is $75 \mathrm{~cm}$. Travel distance is set as $6.2 \mathrm{~cm}$ and in order to meet the production constraints, the solution requires the operator to lift at an average rate of 0.7 lifts per minute for relatively high duration of 407 minutes. Approximately, these design parameters provide RWL and LI as $15.8963 \mathrm{~kg}$ and 2.0 respectively.

\subsection{Performing 100 lifts at $47.7064 \mathrm{~kg}$ per lift (Condition 5)}

Condition 5 represents a heavy load with less repetition. Note that this condition is the risky lifting procedure in all six conditions, so that, $\mathrm{LI}$ is set to 3.0 by the ergonomist. The task is required to perform in less than 3.3 hours and required a heavy load $(47.7064 \mathrm{~kg}$ ). Table 10 contains 10 Run Harmony Search design solutions. The fourth solution suggests that the load can be grasped between 25.4 and $30 \mathrm{~cm}$ horizontally away from the ankles at the start of the lift. The amount of twisting permits the operator to turn $16^{\circ}$. The lifting duration is 54.1 minutes with a 1.8 lifts per minute. These design parameters provide RWL and LI as $15.9019 \mathrm{~kg}$ and 2.0 respectively.

\subsection{Performing 2400 lifts at $5.4536 \mathrm{~kg}$ per lift (Condition 6)}

Condition 6 is a repetitive lifting task with a light load. Design solution \#4 in Table 11 can be explained as follows; the load can be grasped between 25.4 and $27 \mathrm{~cm}$ horizontally away from the ankles at the start of the lift. The amount of twisting permits the operator to turn $50^{\circ}$. The lifting duration is 465 minutes with a 5.1 lifts per minute. These design parameters provide RWL and LI as $5.4336 \mathrm{~kg}$ and 1.0 respectively.

These results shows that proposed Harmony Search algorithm can easily adopted to lifting design parameters and it gives sufficient design parameters similar to Genetic Algorithm.

\section{CONCLUSIONS}

Optimal designing a manual material lifting process carries weight with reducing stresses placed on the low back of human body. Lifting tasks must be carefully designed in order to decrease high-priced Low-back injuries problems. Unfortunately, despite the fact that the lifting problems are critical and important in many industries, it has not achieved the prominence. In this study, NIOSH revised optimal lifting equations were used to find optimal lifting designs for this issue. The main complexity of the problem consists of the large number of unknown potential design combinations of lifting parameters. Six different industrial lifting problems were considered with different physical conditions according to the weight of lifting object, productivity plans, and workplace limitations such as travelling distance, repetition of the task, and duration. A strong meta-heuristic algorithm, Harmony Search, was modeled and presented to find near optimal work place design for given industrial limitations.

This paper aimed to get acceptable lifting designs, which provide ergonomic workplace conditions, by using Harmony Search algorithm and considering NIOSH revised lifting equation to minimize low back pain that occurs in lifting tasks. The developed algorithm provided multiple workplace designs as different harmonies with respect to work practices guide. Each harmony was evaluated to achieve optimal designs by using raw goodness and lifting index equations. Because the Harmony Search algorithm is an iterative heuristic approach, it gives many alternative designs, which are different from each other. Thus, Harmony Search algorithm can be used, as a proper method for the problem of workplace design requires lifting task in many industries. This study is the first attempt to develop and implement a Harmony Search algorithm for the workplace lifting design problem. The results of proposed algorithm were compared with genetic algorithm in the literature. It can be concluded that the proposed algorithm gave similar results with current approach

\section{REFERENCES}

[1] A. Garg, S. Boda, K. T. Hegmann, J. S. Moore, J. M. Kapellusch, P. Bhoyar, M. S. Thiese, A. Merryweather, G. Deckow-Schaefer, D. Bloswick, and E. J. Malloy, "The NIOSH Lifting Equation and Low-Back Pain, Part 1 Association With Low-Back Pain in the BackWorks Prospective Cohort Study," Hum. Factors J. Hum. Factors Ergon. Soc., vol. 56, no. 1, pp. 6-28, Feb. 2014.

[2] X. Xu, C.-C. Chang, G. S. Faber, I. Kingma, and J. T. Dennerlein, "Estimation of 3-D peak L5/S1 joint moment during asymmetric lifting tasks with cubic spline interpolation of segment Euler angles," Appl. Ergon., vol. 43, no. 1, pp. 115-120, Jan. 2012.

[3] S. Srivastava, K. Srivastava, N. Swati, Y. K. Anand, and V. Soamidas, "Designing lifting task in shoe industry using genetic algorithm," in 2010 IEEE International Conference on Industrial Engineering and Engineering Management (IEEM), 2010, pp. 502-506.

[4] N. A. Nelson and R. E. Hughes, "Quantifying relationships between selected work-related risk factors and back pain: a systematic review of objective biomechanical measures and cost-related health outcomes," Int. J. Ind. Ergon., vol. 39, no. 1, pp. 202 210, 2009.

[5] S. Singh and S. Kumar, "Factorial analysis of lifting task to determine the effect of different parameters and interactions,” J. Manuf. Technol. Manag., vol. 23, no. 7, pp. 947-953, Sep. 2012. 
[6] D. Hoy, P. Brooks, F. Blyth, and R. Buchbinder, "The Epidemiology of low back pain," Best Pract. Res. Clin. Rheumatol., vol. 24, no. 6, pp. 769-781, Dec. 2010.

[7] M.-L. Lu, T. Waters, E. Krieg, and D. Werren, "Efficacy of the Revised NIOSH Lifting Equation to Predict Risk of Low Back Pain Associated With Manual Lifting A One-Year Prospective Study," Hum. Factors J. Hum. Factors Ergon. Soc., p. 0018720813513608, Dec. 2013.

[8] W. S. Marras, S. A. Lavender, S. A. Ferguson, R. E. Splittstoesser, and G. Yang, "Quantitative Dynamic Measures of Physical Exposure Predict Low Back Functional Impairment:," Spine, vol. 35, no. 8, pp. 914923, Apr. 2010.

[9] K. Matsudaira, H. Konishi, K. Miyoshi, T. Isomura, K. Takeshita, N. Hara, K. Yamada, and H. Machida, "Potential Risk Factors for New Onset of Back Pain Disability in Japanese Workers: Findings From the Japan Epidemiological Research of Occupation-Related Back Pain Study," Spine, vol. 37, no. 15, pp. 1324-1333, Jul. 2012.

[10] J. L. Vandergrift, J. E. Gold, A. Hanlon, and L. Punnett, "Physical and psychosocial ergonomic risk factors for low back pain in automobile manufacturing workers," Occup. Environ. Med., vol. 69, no. 1, pp. 29-34, Jan. 2012.

[11] B. J. Carnahan and M. S. Redfern, "Application of genetic algorithms to the design of lifting tasks," Int. J. Ind. Ergon., vol. 21, no. 2, pp. 145-158, Feb. 1998.

[12] P. G. Dempsey, "Usability of the revised NIOSH lifting equation," Ergonomics, vol. 45, no. 12, pp. 817-828, Oct. 2002.

[13] M. L. L. R. Okimoto and E. R. Teixeira, "Proposed procedures for measuring the lifting task variables required by the Revised NIOSH Lifting Equation - A case study," Int. J. Ind. Ergon., vol. 39, no. 1, pp. 15-22, Jan. 2009.

[14] S. J. Russell, L. Winnemuller, J. E. Camp, and P. W. Johnson, "Comparing the results of five lifting analysis tools," Appl. Ergon., vol. 38, no. 1, pp. 91-97, Jan. 2007.

[15] T. R. Waters, M.-L. Lu, and E. Occhipinti, "New procedure for assessing sequential manual lifting jobs using the revised NIOSH lifting equation," Ergonomics, vol. 50, no. 11, pp. 1761-1770, Oct. 2007.

[16] NIOSH, Applications Manual for the Revised NIOSH Lifting Equation (94-110). 1994.

[17] T. R. Waters, V. Putz-Anderson, A. Garg, and L. J. Fine, "Revised NIOSH equation for the design and evaluation of manual lifting tasks," Ergonomics, vol. 36, no. 7, pp. 749-776, Jul. 1993.

[18] Z. W. Geem, J. H. Kim, and G. V. Loganathan, "A New Heuristic Optimization Algorithm: Harmony Search," SIMULATION, vol. 76, no. 2, pp. 60-68, Feb. 2001.

[19] K. S. Lee and Z. W. Geem, "A new meta-heuristic algorithm for continuous engineering optimization: harmony search theory and practice," Comput. Methods Appl. Mech. Eng., vol. 194, no. 36-38, pp. 3902-3933, Sep. 2005.

[20] A. Garg, J. M. Kapellusch, K. T. Hegmann, J. S. Moore, S. Boda, P. Bhoyar, M. S. Thiese, A. Merryweather, G. Deckow-Schaefer, D. Bloswick, and E. J. Malloy, "The NIOSH Lifting Equation and Low-Back Pain, Part 2 Association With Seeking Care in the BackWorks Prospective Cohort Study," Hum. Factors J. Hum. Factors Ergon. Soc., vol. 56, no. 1, pp. 44-57, Feb. 2014.

[21] C. C. Chang, D. R. Brown, D. S. Bloswick, and S. M. Hsiang, "Biomechanical simulation of manual lifting using spacetime optimization," J. Biomech., vol. 34, no. 4, pp. 527-532, Apr. 2001

[22] D. J. Blood and S. J. Ferriss, "Effects of background music on anxiety, satisfaction with communication, and productivity," Psychol. Rep., vol. 72, no. 1, pp. 171-177, Feb. 1993.

[23] C. J. Cruise, F. Chung, S. Yogendran, and D. Little, "Music increases satisfaction in elderly outpatients undergoing cataract surgery," Can. J. Anaesth., vol. 44, no. 1, pp. 43-48, Jan. 1997.

[24] D. Evans, "The effectiveness of music as an intervention for hospital patients: a systematic review," J. Adv. Nurs., vol. 37, no. 1, pp. 8-18, Jan. 2002.

[25] M. S. Minor, T. Wagner, F. j. Brewerton, and A. Hausman, "Rock on! An elementary model of customer satisfaction with musical performances," J. Serv. Mark., vol. 18, no. 1, pp. 7-18, Jan. 2004.

[26] M. Morrison, S. Gan, C. Dubelaar, and H. Oppewal, "Instore music and aroma influences on shopper behavior and satisfaction," J. Bus. Res., vol. 64, no. 6, pp. 558 564, Jun. 2011.

[27] C. Thrane, "Music Quality, Satisfaction, and Behavioral Intentions Within a Jazz Festival Context," Event Manag., vol. 7, no. 3, pp. 143-150, Mar. 2002.

[28] N. R. Sabar and G. Kendall, "Using harmony search with multiple pitch adjustment operators for the portfolio selection problem," in 2014 IEEE Congress on Evolutionary Computation (CEC), 2014, pp. 499-503.

[29] K. Z. Gao, P. N. Suganthan, Q. K. Pan, T. J. Chua, T. X. Cai, and C. S. Chong, "Discrete harmony search algorithm for flexible job shop scheduling problem with multiple objectives," J. Intell. Manuf., pp. 1-12, Jan. 2014.

[30] M. R. Maheri and M. M. Narimani, "An enhanced harmony search algorithm for optimum design of side sway steel frames," Comput. Struct., vol. 136, pp. 78-89, May 2014.

[31] X.-S. Yang, "Harmony Search as a Metaheuristic Algorithm," in Music-Inspired Harmony Search Algorithm, Z. W. Geem, Ed. Springer Berlin Heidelberg, 2009, pp. 1-14. 